\title{
El forum hispano: cambios en su configuración entre la República y el Imperio (II a. C. - I d. C.)
}

\section{The forum in Hispania: changes in its configuration between the Republic and the Empire (2nd c. BC to lst c. AD)}

\author{
Francisco MARFIL VÁZquez \\ Universidad de Huelva. Facultad de Humanidades. Laboratorio de Arqueología \\ Avda. Tres de Marzo, s/n, pabellón 12, E-21071 Huelva \\ fmarfilvazquez@gmail.com
}

Los cambios producidos en el modelo de Estado romano desde su fundación hasta su expansión por la totalidad del Mediterráneo supusieron la evolución de los centros cívicos en los cuales se representaba el poder. La llegada y posterior dominio de la península ibérica por parte de Roma supusieron un cambio determinante en la configuración de los fora ubicados en dichas provinciae, coincidiendo con el paso de un modelo republicano hacia uno de corte imperial y unipersonal. Estos cambios quedaron reflejados en la evolución de los arquetipos forenses desarrollados en esta etapa, importados desde la Urbs hacia las capitales provinciales como centros difusores.

\section{PALABRAS CLAVE}

ARQUITECTURA PÚBLICA, HISPANIA, ARQUETIPOS FORENSES, PROVINCIALIZACIÓN, MONUMENTALIZACIÓN

The changes produced in the Roman State model from its foundation to its expansion throughout the Mediterranean brought with it the evolution of the civic centers in which power was represented. The arrival and subsequent domination of the Iberian Peninsula by Rome led to a decisive change in the configuration of the fora located in these provinciae, marked by the evolution from a Republican model to an imperial one, individual and unidirectional. These changes were reflected the evolution of fora archetypes developed at this stage and imported from the Urbs to the provincial capitals which acted as centres of their diffusion.

\section{KEYWORDS}

PUBLIC ARCHITECTURE, HISPANIA, FORA ARCHETYPES, PROVINCIALIZATION, MONUMENTALIZATION 


\section{Introducción}

El forum como conjunto arquitectónico compuesto por una serie de edificios que acogían las funciones políticas, administrativas, judiciales y religiosas articulados en torno a una plaza porticada, es un concepto que se fue definiendo a medida que iba evolucionando y adaptándose a las necesidades específicas de cada etapa. En este sentido, el modelo forense que se erige como célula básica de gobierno por todo el Occidente romano no es más que el resultado final de un largo proceso evolutivo en el cual jugarán un papel determinante la adaptación de la arquitectura griega a los modelos etrusco-itálicos y, posteriormente, la construcción de los denominados foros imperiales (Russell, 1968; Martin, 1972; Coarelli, 1983, 1985, 1992; Balty, 1994; Domínguez, 1995, 2009; Gros, 1996; Etxebarria, 2008).

Debido al papel que jugaban como centro político, judicial y religioso, estos complejos públicos monumentales han sido ampliamente tratados por la historiografía, destacando la figura de José Luis Jiménez Salvador (1987a y b, 1998, 2004, 2009) en el contexto de Hispania, además de los referentes de la arquitectura forense y público-monumental romana, como Pierre Gros, Filippo Coarelli, Jean-Charles Balty, Lucrezia Ungaro o Eugenio La Rocca, cuyas investigaciones suponen la base para cualquier trabajo centrado en esta temática. Asimismo, el análisis de los fora localizados en la península ibérica ha motivado la celebración de varias reuniones científicas y obras monográficas que se antojan imprescindibles (entre otras: AA. VV., 1987; Ramallo, 2004; Nogales, 2009; Noguera, 2009; Soler et al., 2013).

Si bien en este proceso son varios los hitos que las investigaciones han definido como claves, el paso de un estado republicano y principalmente concentrado en la península italiana a una potencia de corte imperial que ejercía su dominio por la totalidad del Mediterráneo se postula como el más determinante de ellos. Esta evolución se desarrolló de forma paulatina y afectó, como no podía ser de otra manera, al corazón político del mundo romano, un escenario donde se debía plasmar la dignitas y el status de estas (Vitr., De arch. V, 1, 2), conformando un paisaje monumental que desarrollaba los arquetipos que los propios emperadores estaban construyendo en la urbs.

Este momento determinante en la historia de Roma entre el siglo in a. C. y la primera mitad del i d. C., en el cual se produce la gran expansión por el Mare Nostrum, afectará de forma directa al territorio hispano, siendo escenario de los conflictos bélicos que la erigieron como la primera potencia del Mediterráneo y los enfrentamientos civiles que marcaron estas centurias. De esta manera, en apenas dos siglos la península ibérica pasará de ser un territorio fragmentado y profundamente desigual a una de las provinciae más prósperas del Imperio. Este salto cualitativo se verá reflejado en la evolución de sus conjuntos forenses, los cuales se verán afectados por las políticas municipalizadoras llevadas a cabo en el territorio y que provocarán oleadas o impulsos monumentalizadores que modificarán estos paisajes públicos e incorporarán los nuevos arquetipos imperiales que se estaban desarrollando en la metrópoli (Goffaux, 2003; Beltrán, 2010; Bermejo et al., 2018; Marfil et al., 2018; Ruiz Bueno, 2018). 


\section{Justificación y metodología}

La incorporación del territorio peninsular al dominio romano se producirá de forma paulatina; la extensión del segundo conflicto contra la potencia cartaginesa por el control del Mediterráneo y los conflictos intestinos de la propia República romana dejarán tras de sí una sucesión de asentamientos militares, deducciones coloniales y ciudades adheridas a la metrópoli que se dotarán de los espacios necesarios para su gobierno. Se han constatado una notable cantidad de conjuntos forenses:

\section{Prov. Lusitania}

Aeminium (Coímbra), Ammaia (Marvão), Augusta Emerita (Mérida), Bobadela (Loures), Capara (Cáparra), Civitas Cobelcorum (Figueira de Castelo Rodrigo), Civitas Igaeditanorum (Idanha-a-Velha), Conimbriga (Conimbriga), Ebora (Évora), Mirobriga (Ciudad Rodrigo), Pax Iulia (Beja), Seilium (Tomar) y Tongobriga (Freixo).

\section{Prov. Tarraconensis}

Asturica Augusta (Astorga), Barcino (Barcelona), Bilbilis (Calatayud), Bracara Augusta (Braga), Caesar Augusta (Zaragoza), Carthago Nova (Cartagena), Clunia Sulpicia (Coruña del Conde Peñalba de Castro), Complutum (Alcalá de Henares), Emporiae (San Martín de Ampurias), Ercavica (Cañaveruelas), Iuliobriga (Retortillo), La Cabañeta (El Burgo de Ebro), Lucentum (Alicante), Municipium Labitolosanum (La Puebla de Castro), Pollentia (Alcudia), Saguntum (Sagunto), Santa Criz de Eslava (Eslava), Segobriga (Saelices), Tarraca (Los Bañales), Tarraco (Tarragona), Termes (Tiermes), Uxama (Osma), Valentia (Valencia) y Valeria (Valeria).

\section{Prov. Baetica}

Arucci (Aroche), Astigi (Écija), Baelo Claudia (Bolonia), Carmo (Carmona), Carteia (San Roque), Celti (Peñaflor), Colonia Patricia (Córdoba), Contributa Iulia (Medina de las Torres), Florentia Iliberritana (Granada), Hispalis (Sevilla), Ilipa Magna (Alcalá del Río), Italica (Santiponce), Ituci (Baena), Munigua (Villanueva del Río y Minas), Nertobriga (Fregenal de la Sierra) y Regina (Casas de Reina).

Si bien no todos conservan evidencias suficientes ni sus fases iniciales pueden situarse en estos primeros momentos. De esta manera, la fase inicial del fenómeno forense hispano viene definida por una implantación parcial del mismo en el territorio.

La pluralidad cultural existente en la península determinó en buena medida la mayor o menor aceptación del dominio de la potencia itálica, afectando al papel que cada ciudad o población desempeñará en los mencionados conflictos bélicos. Una participación cuyas consecuencias significaron el arrasamiento de ciudades, fundaciones de nuevo cuño o promociones de algunos núcleos como retribución a su participación (Remesal, 2005 : 469-476; Beltrán, 2010). En este contexto de conquista y pacificación se identifica una profunda diferencia entre aquellas ciudades que contaban con una mayor tradición urba- 
na, colocándose en una posición de poder con respecto a las poblaciones de su entorno, y aquellas comunidades de carácter menor, que hasta el momento habían ocupado un plano secundario, generalmente alejadas de los puertos comerciales y grandes núcleos que controlaban el territorio (Bendala, 1989: 127-147, 1999: 15-36, 2000-2001: 413-432, 2003: 15-35). En este sentido, la movilización de tropas itálicas a la Bética será determinante para la creación de estos primeros centros cívicos, al traer consigo las fórmulas arquitectónicas propias de Roma y la península itálica.

Aunque el forum republicano es una realidad esquiva debido al arrasamiento y amortización de la práctica totalidad de sus estructuras durante los procesos posteriores de ampliación y monumentalización, algunos de ellos han conservado evidencias que permiten identificar su configuración primigenia. Las modificaciones llevadas a cabo por Augusto durante la conformación de su nueva idea de Estado marcarán un punto de inflexión en la configuración de los fora provinciales, incluyendo el concepto de marmorización, iniciándose el culto imperial, introduciendo la configuración tripartita con la aedes y la basílica enfrentadas entre sí, monopolizando los lados cortos de la plaza y expulsando las funciones comerciales a recintos específicos o macella (Torrecilla, 2007; Etxebarria, 2008: 31-32; Marfil et al., 2018: 293).

En la práctica, estos cambios se produjeron de forma paulatina y no todos fueron implantados en todos los conjuntos forenses; de este modo, en nuestro trabajo hemos realizado un análisis comparativo de todos aquellos estudios llevados a cabo en los conjuntos hispanos para identificar los cambios que se produjeron durante este periodo. Igualmente se ha prestado una especial atención a una serie de indicadores que influyen, como se expondrá en los apartados siguientes, en los procesos de adopción e implantación de las modificaciones de los modelos o arquetipos forenses, tales como la ubicación de la ciudad, su cercanía con respecto a los grandes centros comerciales, políticos o productores, la naturaleza de su oligarquía, etc.

\section{Resultados}

Para comenzar con el análisis del modelo republicano, en lo que respecta a la configuración del recinto, el estudio de los centros forenses de Colonia Patricia (Ventura, 2009; Almoguera, 2011 ), Municipium Emporiae (Mar y Ruiz de Arbulo, 1990), Ituci Virtus Iulia (Ventura, 2014) y Conimbriga (Correia, 2013) muestra unos cambios significativos entre finales del siglo I a. C. y comienzos del i d. C. Las dos primeras ciudades cuentan con una secuencia evolutiva similar, un campamento militar que convive con el poblamiento indígena y el desarrollo de políticas de castigo tras apoyar al bando pompeyano contra César durante el conflicto civil. El conjunto patriciense fue construido en torno al in a. C., compuesto por una plaza porticada y pavimentada con un canal perimetral para desaguar la zona durante las lluvias, aunque en un primer momento el suelo estuviera compuesto por tierra apisonada, 
fechándose su pavimentación en un momento tardoaugusteo (Márquez, 1998: 174-175). Tras las guerras cesarianas el conjunto se monumentaliza en el contexto de las reformas augusteas, constatándose la existencia de la basílica a partir del año 48 a. C. gracias a las fuentes (fig. 1A) (Ventura, 2007: 98; Almoguera, 2011: 42; Garriguet, 2017: 253). Por su parte, las primeras evidencias del conjunto emporitano se sitúan en la segunda mitad del siglo i a. C., constatándose profundas reformas en torno al cambio de Era, entre las que se incluía la construcción de la basílica (fig. 1B) (Mar y Ruiz de Arbulo 1990; Aquilué et al., 2012: 22-49).
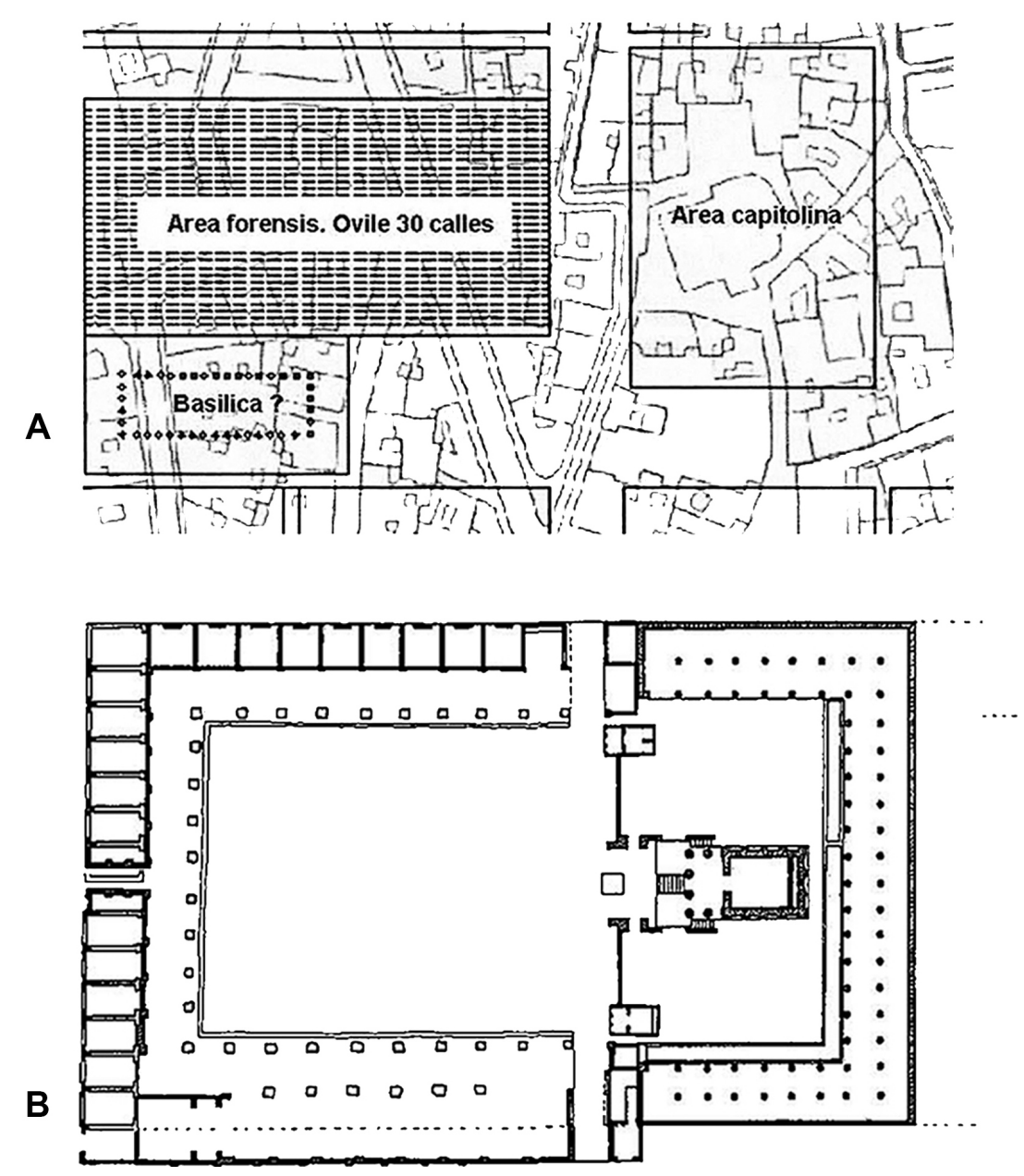

Figura 1. Comparativa de los foros de A) Colonia Patricia (Ventura, 2009: 384) y B) Emporiae (editado a partir de Mar y Ruiz de Arbulo, 1990: 146). 
Por su parte, el foro de la colonia de Ituci Virtus Iulia se conformó tras la deductio de unos 500 veteranos itálicos entre el 30-27 a. C. (Ventura, 2014), lo que suponía la importación directa a este pequeño núcleo urbano de los arquetipos que se estaban desarrollando en la Urbs, como evidencia su notable conjunto escultórico (Márquez, 2014). Pese a su construcción en época augustea, presenta una fase tiberiana donde se advierten profundos cambios en su configuración, pavimentándose la plaza, eliminando el porticado doble del lado sur, añadiendo el edificio basilical y marmorizando algunos de sus ambientes (fig. 2A) (Ventura, 2014: 69-73). Aunque el uso de la porticus duplex en espacios forenses se constata ya en los complejos de la península italiana, como en Minturnae desde el 191 a. C., erigiéndose como un elemento típico del periodo republicano (Etxebarria, 2008: 126 y 128 130). De igual manera, el conjunto de la ciudad romana de la actual Conimbriga presenta sucesivas fases, destacando los cambios que experimenta entre su fase claudio-neroniana y flavia (fig. 2B) (Correia, 2013).

Las evidencias del conjunto patriciense certifican la inclusión del edificio basilical en los esquemas compositivos forenses hispanos preexistentes a partir de época cesariana. Su pronta incorporación a la órbita de Roma, además de su papel destacado como capital administrativa desde los primeros compases de su presencia en la península, explica las fechas tempranas de la incorporación de estos cambios en su arquetipo forense. Por su parte, el conjunto emporitano, al igual que el colonial de Tarraco (Mar et al., 2010: 58), incorporarán el edificio basilical algunos decenios más tarde, en torno al cambio de Era, aunque el conjunto tarraconense no mantendrá el esquema compositivo de los otros dos conjuntos - un forum longitudinal dividido en dos por una vía que separa el ambiente sacro de la zona donde se dispondrían las tabernae y el resto de espacios funcionales, contando con una porticus duplex en uno de sus lados largos que sería sustituida por la basílica o acogería las funciones judiciales-, sino que construirá un complejo anexo al anterior presidido por la basílica (fig. 3).

En lo que respecta a las otras ciudades referidas, aunque la colonia itucitana se destaca por la inmediata importación de los arquetipos itálicos debido a la naturaleza de sus colonos, no será hasta época tiberiana cuando incorpore un edificio basilical independiente, momento en el cual adoptará el modelo compositivo de forum tripartito, con la aedes y el edificio basilical enfrentados y eliminando la porticus duplex, que en origen ocupaba el margen sur y este de su plaza, como se indica en la imagen (fig. 2A) (Ventura, 2014). Un hecho igualmente constatado en el conjunto de Conimbriga, donde aún en época claudio-neroniana el forum mantiene una configuración que podríamos denominar como cesariano-augustea, con la basílica o porticus duplex en uno de los lados largos del conjunto, composición que cambiará en la oleada monumentalizadora de época flavia (Marfil et al., 2018), adoptando una configuración tripartita y convirtiéndose en un recinto meramente dedicado al culto imperial (Correia, 2009). De este modo, las modificaciones en la configuración del forum patriciense parecen destacarse como las más tempranas del fenómeno forense hispano, una circunstancia que podría estar estrechamente relacionada con el arrasamiento de la ciudad por tropas cesarianas durante el conflicto cesariano-pompeyano (Vaquerizo, 201 1: 186). Ya en torno al 


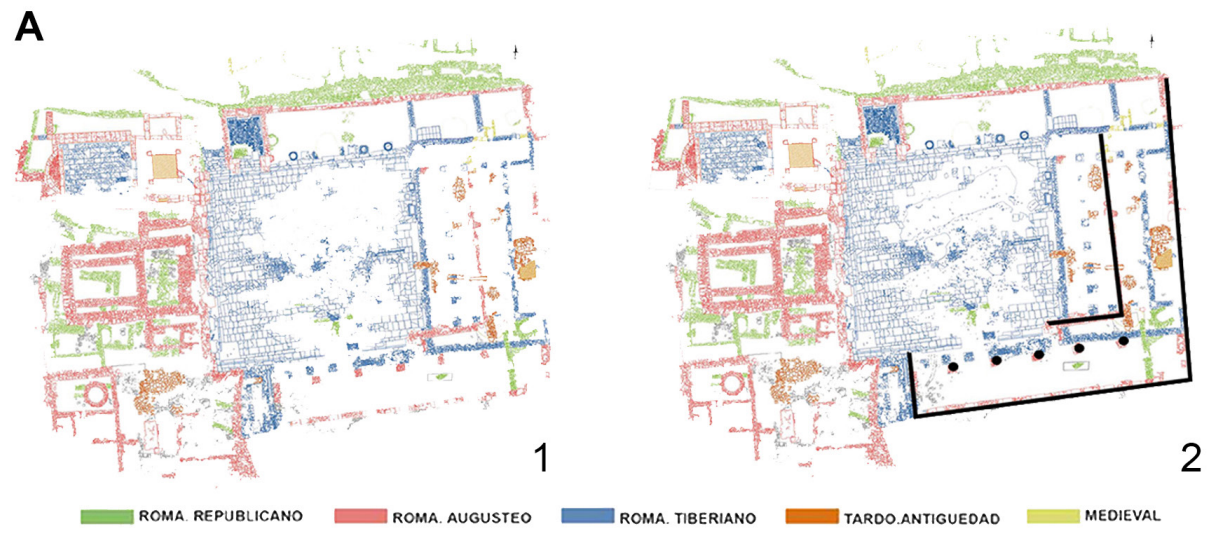

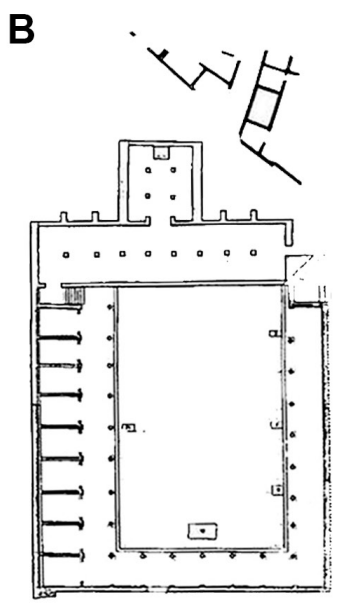

1

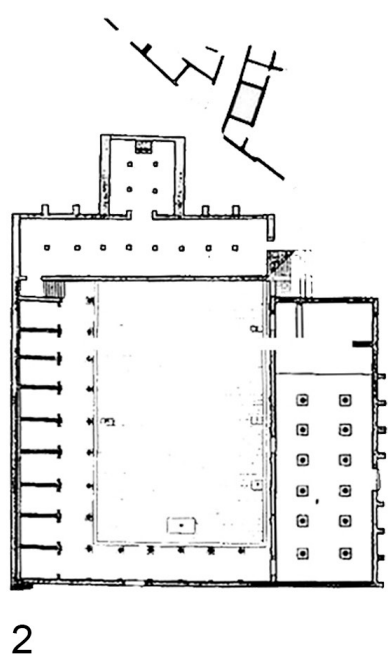

2

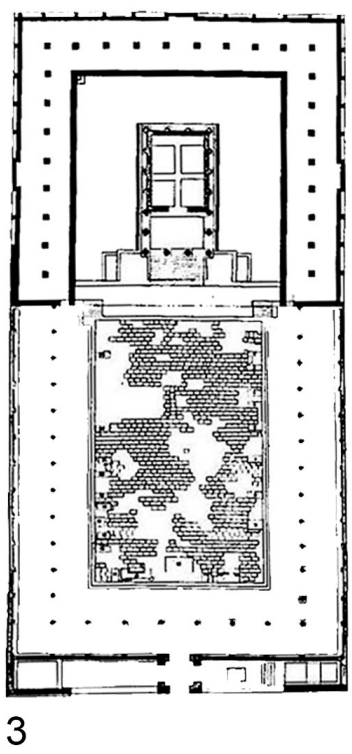

Figura 2. Comparativa de los foros de A) Ituci (editado a partir de Ventura, 2014: 71) y B) Conimbriga: fases augustea (1), claudioneroniana (2) y flavia (3) (Correia, 2013: 354).

cambio de Era, bajo el principado augusteo, se irán incorporando los arquetipos cesarianos a otros fora ya citados, como el emporitano, tarraconense o itucitano.

Por otro lado, si tenemos en cuenta la condición particular de la fundación de Ituci, su deductio se produjo entre el 30 y el 27 a. C., derivando en la monumentalización y revolución urbanística de la misma durante el siglo i d. C. que la dotara de las infraestructuras necesarias para la administración municipal y estuviera acorde con su nueva dignitas 


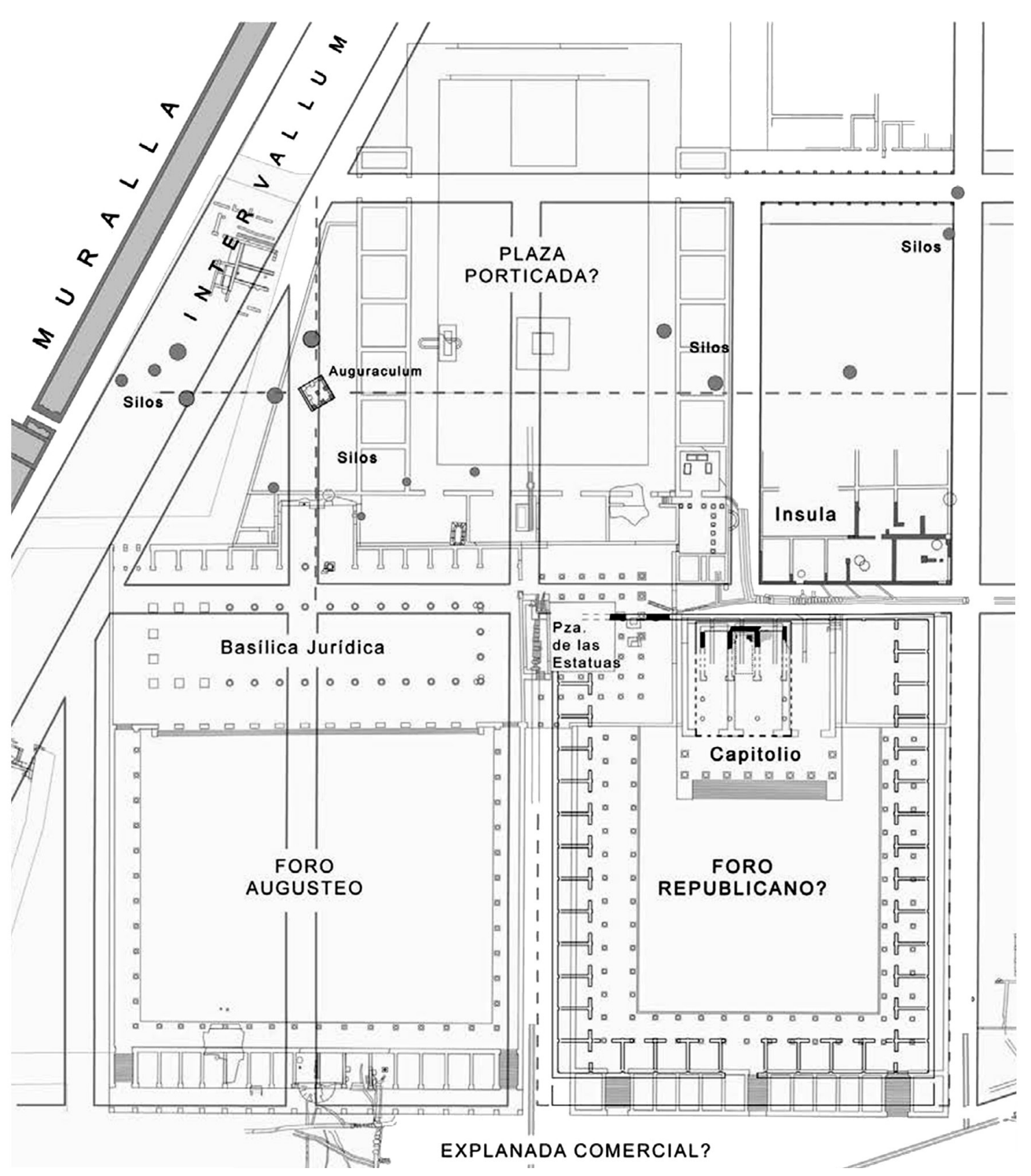

Figura 3. Planta del forum colonial de Tarraco tras las reformas augusteas (editado a partir de Ruiz de Arbulo, 2015: 160).

(Ventura, 2014). Como ya se ha indicado, el modelo compositivo de su foro en estos primeros momentos no se ajustaba al modelo tripartito asociado a la herencia augustea derivado del propio Forum Augustum (Zanker, 1984; Ventura, 2006); esta circunstancia supone que la implantación de la configuración tripartita en los fora hispanos no se constate hasta como mínimo los momentos finales del reinado de Augusto o principios del de Tiberio. En este 
sentido, otros conjuntos hispanos de configuración tripartita como los de Augusta Emerita o Baelo Claudia presentan información dispar en torno a sus edificios basilicales, siendo estos determinantes en dicha configuración. Así, en el conjunto emeritense se desconoce si existía tal espacio antes de la monumentalización de época flavia (Ayerbe et al., 2009: 810 y 818 ). En cambio, para el municipium gaditano se presenta una cronología de mediados del siglo i d. C. o principios del II d. C., según su decoración arquitectónica, aunque se suponga un edificio previo ligeramente desplazado más hacia el sur (Fellague, 2013, 2016).

Si ampliamos el análisis al conjunto peninsular, las evidencias conservadas del resto de foros hispanos revelan una variada casuística en lo concerniente a la configuración y composición de las plazas a partir de época augustea; de esta forma, la sustitución de los porticados dobles por los edificios basilicales y la adopción de una configuración tripartita serán procesos complejos y que se producirán de forma paulatina, llegando incluso a no producirse en algunos ejemplos.

De entre los conjuntos que presentan una configuración tripartita se encuentran Contributa Iulia (Mateos y Pizzo, 2014), Astigi (Felipe y Márquez, 2014: 164 y ss.; GarcíaDils, 2015), Ituci (Ventura, 2014) y Baelo Claudia (Sillières, 1997) en la Baetica; Augusta Emerita (Ayerbe et al., 2009) en Lusitania, y Asturica Augusta (Vidal y González, 2018), Clunia (Iglesia y Tuset, 2013), Valentia (Morín y Ribera, 2015) y Valeria (Fuentes y Escobar, 2013 ) en la Tarraconensis. En este grupo cabría incluir el conjunto de Seilium (Ponte, 2010), tripartito; pero debido a su promoción en época flavia y el desconocimiento de sus fases constructivas resulta prudente excluirlo, aunque al igual que Aeminium (Alarcão et al., 2009) fue civitas en época augustea y municipium en época flavia, pudiendo desarrollar una arquitectura forense similar.

Como contrapunto contamos con el complejo forense de Arucci, construido después de su fundación ex novo tras las políticas territoriales augusteas, entre los reinados de Calígula y Claudio. Las investigaciones lo definen como una construcción unifásica (Bermejo, 2013: 130-201), lo que explicaría el mantenimiento de su porticado doble en los lados sur y este (fig. 4). Su avanzada cronología puede deberse a la propia condición de la ciudad: un enclave urbano de rango menor, alejado de los grandes centros de poder y sin un aporte itálico que lo conecte de forma directa con la metrópoli, como ocurre en el caso itucitano.

La circunstancia constatada en el complejo de Arucci parece identificarse en aquellos foros que no son objeto de grandes modificaciones a partir de época tiberiana, manteniendo una porticus duplex o la basílica en los lados largos de sus plazas; así, a los ya citados casos de Colonia Patricia (Ventura, 2009; Almoguera, 2011), Emporiae (Mar y Ruiz de Arbulo, 1990) y Arucci (Bermejo, 2013), se suman los de Bobadela (Simões, 2010), Capara (Cerrillo, 2010) y Mirobriga (Barata, 2010) en Lusitania, y Bilbilis (Martín-Bueno, 1987; MartínBueno y Sáenz, 2004), Lucentum (Olcina et al., 2013), Saguntum (Aranegui y Jiménez, 2013; Aranegui, 2014), Tarraca (Ventura et al., 2018) y Termes (Martínez, 2010) en la Tarraconensis. Al margen quedan otros conjuntos cuya falta de datos impiden determinar su posible configuración, como Barcino (Beltrán de Heredia, 2015), Caesaraugusta (Hernández y Núñez, 1998; Romero, 2014), Civitas Cobelcorum (Simões, 2010) y Civitas Igaeditanorum 


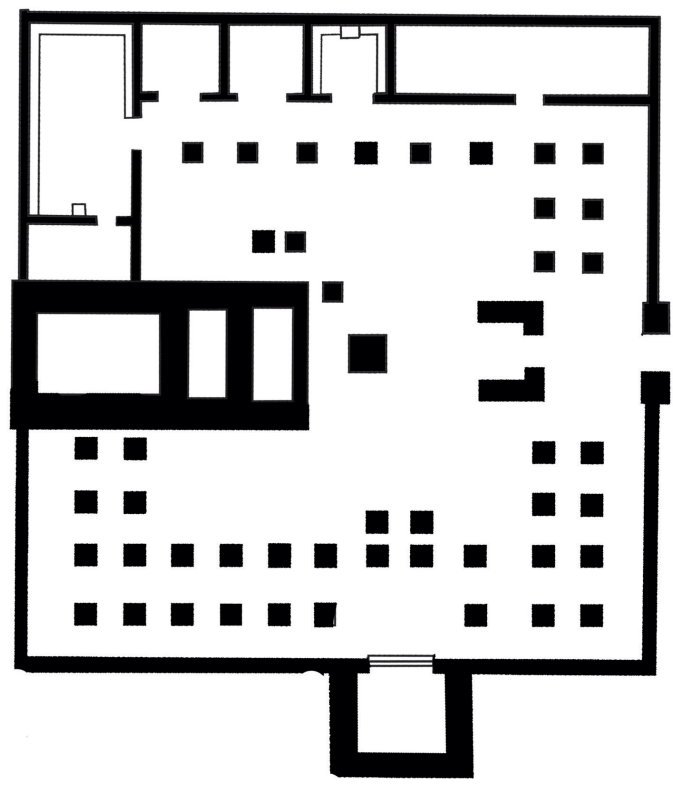

Figura 4. Planta del forum de Arucci (editado a partir de Bermejo, 2013: 131).

(Mantas, 2010), así como el forum de Munigua (Schattner, 2003) encajara dentro de esta casuística, pero podría venir determinado por la limitación espacial de su urbanismo.

Continuando con el análisis de la evolución de la configuración y composición de los fora hispanos, la pervivencia de las tabernae en momentos postaugusteos parece destacarse como una práctica bastante habitual, constatándose en muchos de los conjuntos construidos en momentos augusteos, como el de Conimbriga antes de su reforma flavia (Correia, 2013), Seilium (Ponte, 2010), Caesaraugusta (Hernández y Núñez, 1998), Clunia (Iglesia y Tuset, 2013), Saguntum (Aranegui y Jiménez, 2013), el foro colonial de Tarraco (Ruiz de Arbulo, 2015) y Termes (Martínez, 2010); un hecho que también se reproduce en el caso bético de Baelo Claudia, aunque tras su refectio la zona de tabernae parece quedar en desuso (Sillières, 1997: 119-120). Si bien las reformas llevadas a cabo por Augusto supondrán la expulsión de las funciones comerciales de los fora, dando pie al nacimiento del macellum (Etxebarria, 2008: 31-32), tal y como se ha constatado en Arucci (Bermejo, 2013), Ituci (Ventura, 2014) o Baelo Claudia (Sillières, 1997), la conservación de estos antiguos espacios comerciales debió responder a un cambio de funcionalidad, pudiendo actuar como galerías de summi viri o sacella, un hecho que explicaría la falta de evidencias materiales en las tabernae de Baelo Claudia; al permanecer como nichos que acogerían grupos escultóricos, no presentarían material arqueológico alguno tras los expolios y la amortización de los mismos.

Por último, otro de los elementos que se erigen como definitorios del modelo forense republicano antes de las reformas de César y, principalmente, de Augusto, es el capitolium, como templo principal del complejo. Son pocos los constatados en los contextos forenses hispanos, diferenciándose aquellos de tradición etrusco-itálica, con un solo edificio de 


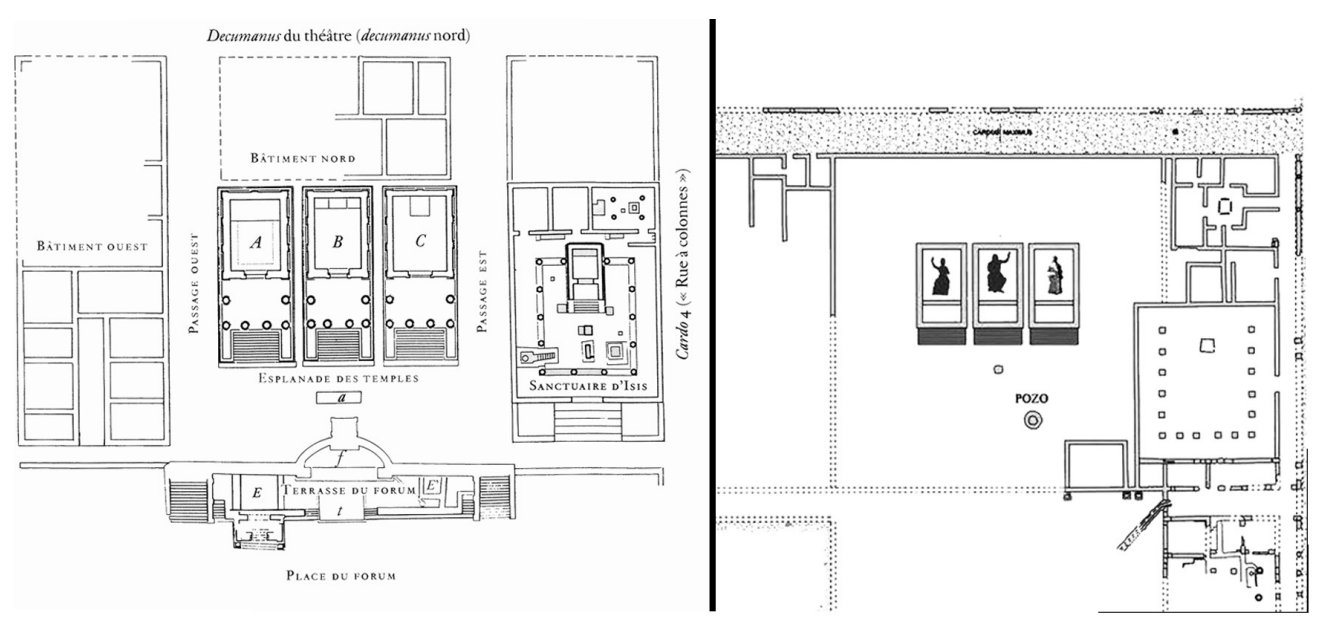

Figura 5. Terraza superior del forum de Baelo Claudia, con los templos capitolinos en el centro (editado a partir de Bonneville et al., 2000: 17), y detalle de los templos del foro de Regina (editado a partir de Aguilar et al., 2014: 1652).

tres cellae, de aquellos donde se constatan tres templos de cella única dispuestos de forma paralela. Los templos capitolinos o etrusco-itálicos herederos de la configuración del auguraculum se han constatado en Pollentia (Vallori, 2012), Saguntum (Aranegui y Jiménez, 2013) y Tarraco (Mar et al., 2015), y su construcción no parece fecharse más tarde de principios o mediados del i a. C., momento a partir del cual se instaura la nueva tipología rectangular y de cella única, influenciada por los modelos helenísticos y que se constata en conjuntos de cronología similar, como Emporiae (Mar y Ruiz de Arbulo, 1990). El propio conjunto colonial de Tarraco presenta hasta tres episodios constructivos en su capitolio, siendo los dos últimos casi consecutivos, pasando de un templo períptero a pseudoperíptero ampliando notablemente la cella, una tipología más acorde con los templos desarrollados en época imperial. En esta tercera fase, fechada a comienzos del i d. C., además se monumentalizará el entorno, insertando un chalcidicum que conectaba la aedes con una nueva plaza que incluirá la basílica. La inserción de ambos espacios resulta una incorporación plenamente augustea, no solo por su adscripción cronológica sino por el propio testimonio de Augusto en su Res Gestae (19.1), donde pone de relieve la construcción del chalcidicum del foro de César (Zevi, 1993; Gros, 2001-2002; Torelli, 2003, 2005).

Como ya se ha comentado, otros complejos forenses presentarán un conjunto templar a caballo entre ambos modelos, incorporando tres templos de cella única, más acorde con la tipología templar desarrollada en época imperial, como en Baelo Claudia (Bonneville et al., 2000) y Regina (Álvarez et al., 2014) en la Provincia Baetica (fig. 5), fechándose ambos complejos en la primera mitad del i d. C. A estos conjuntos presididos por un capitolium cabría añadir el conjunto colonial patriciense, al cual se le supone un área capitolina por su construcción en el in a. C., aunque se desconoce su composición (Ventura, 2009). 


\section{Conclusiones}

Tal y como se ha expuesto en el apartado anterior, algunos de los episodios más determinantes en la historia de Roma acaecidos entre el II a. C. y principios del I d. C. tendrán su correspondiente reflejo en los centros de poder cívico de los territorios sometidos al dominio de la metrópoli. La evolución del sistema de gobierno y del concepto del Estado se reflejará inevitablemente en aquellos complejos que lo representaban y a través de los cuales se identificaba a la propia sociedad local.

Sin embargo, ha quedado patente que la rápida transformación de Roma en un arco cronológico tan reducido, el cual podría incluso limitarse para el caso hispano a la segunda mitad del i a. C., se tradujo en varias modificaciones, que se fueron implantando de una manera gradual en las provinciae en función de una serie de variantes. En este sentido, Hispania será una zona en conflicto hasta el establecimiento de la Pax, lo que obligará a Roma a centrarse en el sometimiento de estas poblaciones, suponiendo una demora en la instauración de políticas territoriales, en las cuales se enmarcan las propias divisiones por provinciae y conventus, hasta el sometimiento total de los pueblos peninsulares. Unos pueblos que no tuvieron un aporte foráneo tan destacado como los afincados en el sur y el levante peninsular, lo que explicará que esta primera fase de implantación o etapa incipiente se concentre en estas últimas, retrasándose o incluso no existiendo en zonas del interior.

De igual modo, debe tenerse en cuenta la actuación directa de Roma sobre las cabezas administrativas y coloniae, destacando las primeras como caput provinciae y siendo el epicentro de las sucesivas oleadas monumentalizadoras que traían aparejadas cambios en el modelo arquitectónico forense, generándose desde ellas un efecto onda, expandiéndose en primera instancia a las capitales conventuales y desde las cuales se difundirán al resto del territorio, influyendo factores como la dignitas y el status de las ciudades receptoras, su proximidad a los grandes centros administrativos o comerciales, la capacidad adquisitiva de sus élites, etc. A este proceso de importación desde la Urbs, se le suma la capacidad económica y material de cada centro urbano para acometer los cambios en sus complejos forenses, midiéndose esta en el tiempo necesario para la implantación de los nuevos modelos y en el número de reformas realizadas; de esta manera, y como ya se ha mencionado en el apartado anterior, algunos fora presentarán varias fases, identificándose notables cambios entre ellas, y otros de menor entidad apenas experimentarán variaciones desde su construcción.

Así se configuraba un sistema territorial estratificado basado en la ciudad como elemento principal, al frente del cual se situaban las cabezas administrativas, seguidas de las coloniae y municipia. Dentro del mismo deben tenerse en cuenta algunos pequeños núcleos cuya fundación se encuadra dentro de las políticas territoriales cesariano-augusteas como centros menores destinados al control y administración del territorio, normalmente con la categoría de municipium o incluso menor, pero que presentan un paisaje monumental destacado. Un fenómeno que incluiría a ciudades como Arucci (Bermejo, 2013) y Munigua (Schattner, 2003) en la Bética; núcleos lusitanos como Aeminium (Alarcão et al., 2009), Civitas Igaeditanorum (Mantas, 2010) o Seilium (Ponte, 2010), y otros tarraconenses como 
Asturica Augusta, Bilbilis (Martín-Bueno, 1987; Martín-Bueno y Sáenz, 2004) o Tarraca (Ventura et al., 2018). Ciudades que debieron contar con una implicación directa o la presencia de la administración imperial, actuando como centros estratégicos de control regional, dado que algunas de ellas no son promocionadas a municipium hasta época flavia pero cuentan ya desde época julio-claudia con un forum donde se ponía de relieve su plena asimilación de los arquetipos romanos.

En este sentido, los múltiples y sustanciales cambios constatados en aspectos tan determinantes como es la propia configuración y composición del forum en apenas cinco decenios en estos conjuntos de tanta significación para el mundo romano y cuya difusión por las provinciae conllevaba unos procesos tan dilatados, dará como resultado múltiples variantes, pese a los esfuerzos de Roma por desarrollar una arquitectura pública homogénea. En consecuencia, se configurará un panorama general donde habrá foros que incorporen de forma inmediata los nuevos arquetipos, como ocurre en Ituci o Conimbriga, donde se pasa de un foro de estilo republicano en época augustea a uno típicamente augusteo tripartito, monumentalizado en época tiberiana y claudio-neroniana respectivamente. Y otros como en Arucci, cuyo foro presenta una construcción unifásica, manteniendo la porticus duplex en sus lados sur y este, típica de la fase tardorrepublicana, pero totalmente cerrado y marmorizado, reproduciendo un estilismo arquitectónico plenamente augusteo. O la propia Baelo Claudia, que, pese a su refectio, mantendrá el capitolium, la tribuna de oradores, las tabernae y una arquitectura sobre piedra local como características del arquetipo tardorrepublicano, junto con la configuración tripartita del conjunto o la incorporación de las aediculae de culto imperial propias de la etapa flavia junto a la tribuna de oradores.

El análisis y condensación de esta evolución destaca cuando se comparan los propios foros de César y Augusto (fig. 6), evidenciándose el cambio de modelo con la eliminación de las tabernae y la implantación de los principios de axialidad y simetría, unas modificaciones en el modelo que llevarán a transformar el complejo cesariano, añadiéndole un ábside en el flanco norte en época trajanea (Amici, 1991: 65 y ss.; Meneghini, 2009: 43-57). De esta forma, el prototipo forense augusteo queda ejemplificado en el Forum Augustum, desarrollando un esquema que se mantendrá sin apenas variantes, como muestra el Forum Traiani (Meneghini, 2009: 117-164), y que se define por combinar algunas características de los arquetipos previos, como la articulación del conjunto en torno a una plaza rectangular porticada y aislada del entorno, con los principios de simetría y axialidad, desarrollados en una configuración tripartita que dará una mayor importancia al edificio basilical, equiparándolo a la aedes, confrontando ambos en un paisaje arquitectónico donde el mármol cobrará una especial significación. Una evolución en la cual la muerte de Augusto supondrá un nuevo hito en el naciente culto imperial, tal y como evidencian las dedicaciones de complejos monumentales al Divus Augustus en los denominados foros provinciales, así como la introducción de ciclos escultóricos donde aparece como una figura idealizada acompañada de otros miembros de su domus. Una práctica que se afianzará durante todo el periodo julio-claudio y dará un salto cualitativo a partir de época flavia, consolidándose y multiplicándose sus manifestaciones tras salvar las dificultades propias 

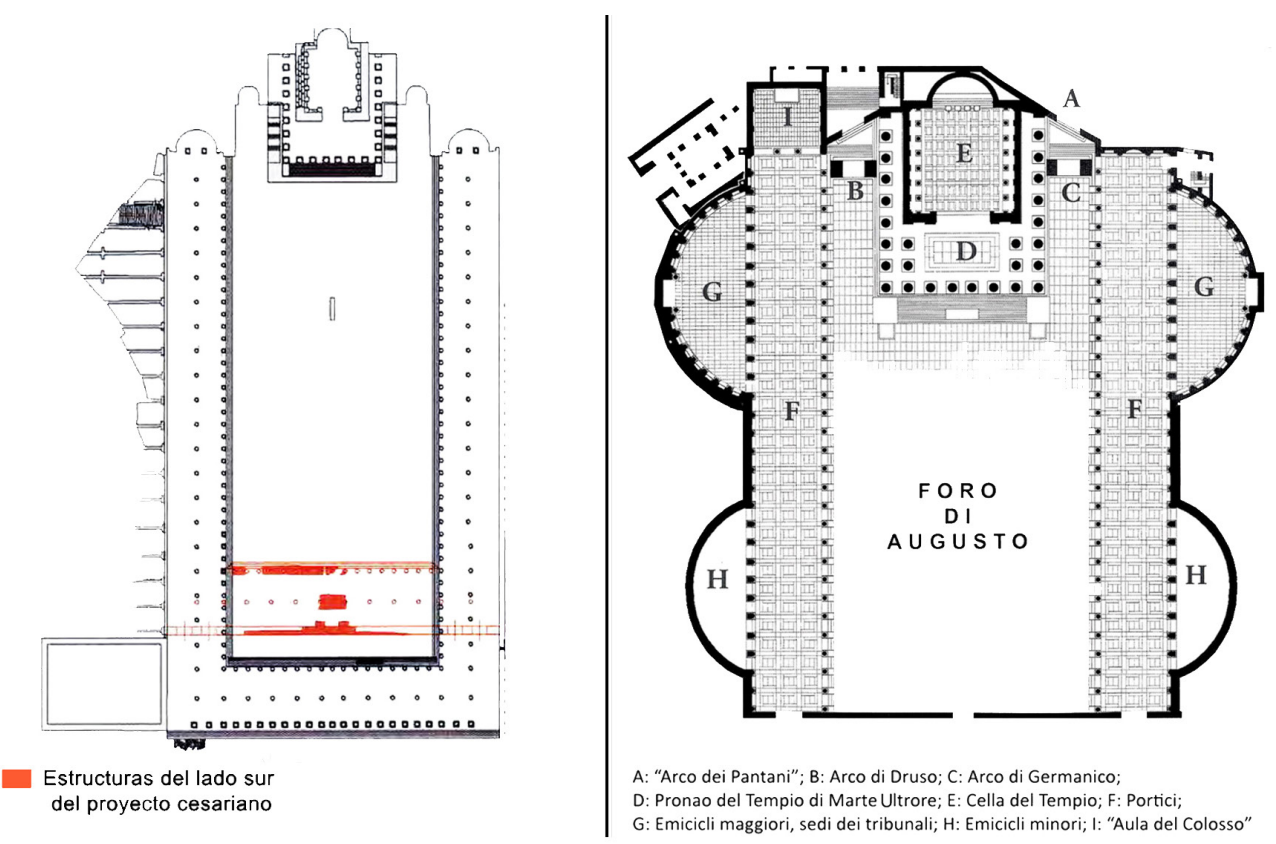

Figura 6. Plantas de los foros imperiales de César (editado a partir de Meneghini, 2009: 47) y Augusto (editado a partir de Meneghini y Santangeli, 2007: 44).

del cambio dinástico y generando un nuevo impulso monumentalizador a partir de la expansión del ius latii a toda Hispania. Este nuevo impulso afectará de manera directa a la inmensa mayoría de núcleos poblacionales, que hasta entonces no contaban con esta categoría, provocando su monumentalización y la incorporación del nuevo arquetipo forense a sus condiciones particulares, ya fuera implantándolo completamente o adaptándolo a la configuración de su forum previo. Esta nueva oleada afectará igualmente a las ciudades ya promocionadas en época cesariano-augustea, siendo por tanto junto con la augustea la de mayor significación en el territorio hispano.

\section{Agradecimientos}

El presente trabajo se enmarca dentro de las actividades de los proyectos de investigación «Del Atlántico al Tirreno ( $2^{\mathrm{a}}$ fase). Los puertos hispanos y su relación comercial con Ostia Antica» (HAR2017-89154-P), perteneciente al Plan Nacional de I+D+I, y «Ciudades romanas de la Bética. Corpus Vrbium Baeticorum II. Conventus Cordubensis et Gaditanus (Proyecto CVB II)" (UHU-1260162), correspondiente a la convocatoria del Fondo Europeo de Desarrollo Regional y la Consejería de Economía y Conocimiento de la Junta de Andalucía. 


\section{Bibliografía}

AA. VV., 1987, Los foros romanos de las provincias occidentales, Madrid.

AGUILAR, J. C., BELLO, J. R., COLLADO, H., CONTRERAS, V., CHAMIZO, J. J., FERNÁNDEZ, R. C., GUERRA, S., MOSQUERA, J. L., PÉREZ, S. y SÁNCHEZ, E., 2014, Nuevos datos sobre el foro romano de Regina, en J. M. ÁLVAREZ, T. NOGALES e I. RODÀ (eds.), Actas XVIII Congreso Internacional de Arqueología Clásica, Mérida, 1651-1653.

ALARCÃO, J., ANDRÉ, P., BARRELAS, P., CARVALHO, P., SANTOS, F. Y SILVA, R. C., 2009, $O$ forum de Aeminium. A busca do desenho original / The Forum of Aeminium: the search for the original design, Lisboa.

ALMOGUERA, J., 2011, El foro colonial, en M. D. BAENA, C. MÁRQUEZ y D. VAQUERIZO (eds.), Córdoba, reflejo de Roma. Catálogo de la exposición, Córdoba, 41-50.

ÁlVAREZ, J. M., SAQUETE, J. C., NOGALES, T. y RODRÍGUEZ, F. G., 2014, El complejo religioso del foro de Regina, en J. M. ÁLVAREZ, T. NOGALES e I. RODÀ (eds.), Actas XVIII Congreso Internacional de Arquelogía Clásica, Mérida, 1639-1642.

AMICI, C. M., 1991, Il foro di Cesare, Firenze.

AQUILUÉ, X., CASTANYER, P., SANTOS, M. y TREMOLEDA, J., 2012, 4. Arquitectura oficial, en X. AQUILUÉ ABADÍAS (ed.), Empúries. Municipium Emporiae, Ciudades romanas de Hispania 6, L'Erma di Bretschneider, Roma, 39-54.

ARANEGUI, C., 2014, Saguntum, en M. H. OLCINA DOMÈNECH (ed.), Ciudades Romanas Valencianas, MARQ, 107-122.

ARANEGUI, C. y JIMÉNEZ, J. L., 2013, La curia de Saguntum, en B. SOLER, P. MATEOS, J. M. NOGUERA y J. RUIZ DE ARBULO (eds.), Las sedes de los ordines decurionum en Hispania. Análisis arquitectónico y modelo tipológico, Anejos de Archivo Español de Arqueología LXVII, Mérida, 43-52.

AYERBE, R., BARRIENTOS, T. y PALMA, F., 2009, Génesis y evolución del foro de Augusta
Emerita, en R. AYERBE, T. BARRIENTOS y F. PALMA (eds.), El foro de Augusta Emerita. Génesis y evolución de sus recintos monumentales, Anejos de Archivo Español de Arqueología LIII, Mérida, 807-831.

BALTY, J.-Ch., 1994, Le centre civique des villes romaines et ses espaces politiques et administratrifs, en X. DUPRÉ RAVENTÓs (coord.), La ciudad en el mundo romano 1, Tarragona, 91-107.

BARATA, M. F., 2010, Caracterização Geral de Miróbriga, en T. NOGALES BASARRATE (ed.), Ciudad y foro en Lusitania Romana, Studia Lusitana 4, Mérida, 201-229.

BELTRÁN, F., 2010, Les colonies latines d'Hispanie (II ${ }^{\mathrm{e}}$ siècle av. n. È.) : émigration italique et intégration politique, en N. BARRANDÓN y F. KIRBIHLER (dirs.), Les gouverneurs et les provinciaux sous la République romaine, Rennes, 131-144.

BELTRÁN DE HEREDIA, J., 2015, Novetats sobre el fòrum de Barcino: la cúria i altres edificis públics, QUARHIS, época II, núm. 11, 126-146.

BENDALA, M., 1989, La génesis de la estructura urbana en la España antigua, Cuadernos de Prehistoria y Arqueología 16, 127-147.

BENDALA, M., 1999, La ciudad en la España antigua, en F. GARCÍA y F. ACOSTA (coords.), Córdoba en la Historia: La Construcción de la Urbe, Córdoba, 15-36.

BENDALA, M., 2000-2001, Estructura urbana y modelos urbanísticos en la Hispania antigua: continuidad y renovación con la conquista romana, Zephyrus 53-54, 413-432.

BENDALA, M., 2003, De Iberia in Hispaniam. El fenómeno urbano, en L. ABAD CASAL (ed.), De Iberia in Hispaniam. La adaptación de las sociedades ibéricas a los modelos romanos, Murcia, 15-35.

BERMEJO, J., 2013, Arucci Turobriga. Civitas et Territorium. Un modelo de implantación territorial y municipal en la Baeturia Celtica, Universidad de Huelva. 
BERMEJO, J., MARFIL, F. y CAMPOS, J. M., 2018, Urbanismo de las ciudades béticas en los Conventus Hispalensis y Astigitanus, en J. M. CAMPOS y J. BERMEJO (eds.), Ciudades romanas de la Provincia Baetica. Corpus Vrbium Baeticarum: Conventus Hispalensis et Astigitanus. CVB I, Onoba Monografías 2, Universidad de Huelva, 209-236.

BONNEVILLE, J. N., FINCKER, M., SILLIÈRES, P., DARDAINE, S. y LABARTHE, J. M., 2000, Belo VII. Le capitole, Collection de la Casa de Velázquez 67, Madrid.

CERRILlO, E., 2010, El foro de Capara, en T. NOGALES BASARRATE (ed.), Ciudad y foro en Lusitania Romana, Studia Lusitana 4, Mérida, 127-136.

COARELLI, F., 1983, Il foro romano. Vol. I: Periodo arcaico, Roma.

COARELLI, F., 1985, Il foro romano. Vol. II: Periodo repubblicano e augusteo, Roma.

COARELLI, F., 1992, Colonizzazione e municipalizzazione: tempi e modi, Dialoghi di Archeologia, $3^{\mathrm{a}}$ serie, 10, 21-30.

CORREIA, V. H., 2009, O forum de Conimbriga e a evolução do centro urbano, en T. NOGALES (ed.), Ciudad y foro en Lusitania Romana, Studia Lusitana 4, Mérida, 89-105.

CORREIA, V. H., 2013, Cúria e basílica na evolução do fórum de Conimbriga, en B. SOLER, P. MATEOS, J. M. NOGUERA Y J. RUIZ DE ARBULO (eds.), Las sedes de los ordines decurionum en Hispania. Análisis arquitectónico y modelo tipológico, Anejos de Archivo Español de Arqueología LXVII, Mérida, 353-362.

DOMínGUEZ, A. J., 1995, Del ágora al foro: los espacios públicos de las ciudades griegas y sus transformaciones en época romana, Boletín de la Asociación Española de Amigos de la Arqueología (Homenaje a Hermanfrid Schubart) 35, Madrid, 229-244.

DOMÍNGUEZ, A. J., 2009, Espacios públicos en transición: del ágora griega al foro romano, en J. M. NOGUERA (ed.), Fora Hispaniae. Paisaje urbano, arquitectura, programas decorativos y culto imperial en los foros de las ciudades hispanorromanas, Monografías del Museo Arqueológico de Murcia 3, 24-36.

ETXEBARRIA, A., 2008, Los foros romanos republicanos en la Italia centro-meridional tirrena. Origen y evolución formal, CSIC, Madrid.

FELIPE, A. M. y MÁRQUEZ, C., 2014, Una propuesta de modulación del Foro Colonial de Astigi y la configuración de su área sacra, Archivo Español de Arqueología 87, 157-173.

FELLAGUE, D., 2013, Décor architectural et datation de la basilique, en P. SILLIÈRES (ed.), Belo IX. La basilique, Collection de la Casa de Velázquez 136, Madrid, 149-216.

FELLAGUE, D., 2016, Sur les datations du décor architectural de Baelo Claudia, II Jornadas Internacionales de Baelo Claudia. Nuevas Investigaciones, Junta de Andalucía, 129-146.

FUENTES, A. y ESCOBAR, R., 2013, El edificio de la curia en el foro de Valeria, en B. SOLER, P. MATEOS, J. M. NOGUERA Y J. RUIZ DE ARBULO (eds.), Las sedes de los ordines decurionum en Hispania. Análisis arquitectónico y modelo tipológico, Anejos de Archivo Español de Arqueología LXVII, Mérida, 215-230.

GARCÍA-DILS, S., 2015, Colonia Augusta Firma Astigi. La evolución urbana de Écija desde la Protohistoria hasta la Antigüedad Tardía, Universidad de Sevilla, Sevilla.

GARRIGUET, J. A., 2017, Religión y culto imperial, en J. F. RODRÍGUEZ NEILA (ed.), La ciudad y sus legados históricos. Córdoba romana, Real Academia de Ciencias, Bellas Letras y Nobles Artes de Córdoba, 249-311.

GOFFAUX, B., 2003, Promotions juridiques et monumentalisation des cités hispano-romaines, Saldvie 3, 143-161.

GROS, P., 1996, L'architecture romaine: $d u$ début du IIIe siècle av. J.-C. à la fin du Haut-Empire. 1. Les monuments publics, París.

GROS, P., 2001-2002, Chalcidicum. Le mot et la chose, Ocnus 9-10, 123-135.

HERNÁNDEZ, J. A. y NÚÑEZ, J., 1998, Nuevos datos para el conocimiento del foro de Caesaraugusta, Empúries 51, 93-104. 
IGLESIA, M. A. y TUSET, F., 2013, El proyecto del Foro de Clunia. Espacio y función, en B. SOLER, P. MATEOS, J. M. NOGUERA Y J. RUIZ DE ARBULO (eds.), Las sedes de los ordines decurionum en Hispania. Análisis arquitectónico y modelo tipológico, Anejos de Archivo Español de Arqueología LXVII, Mérida, 97-110.

JIMÉNEZ, J. L., 1987a, Arquitectura forense en la Hispania romana: bases para su estudio, Universidad de Zaragoza.

JIMÉNEZ, J. L., 1987b, Los modelos constructivos en la arquitectura forense de la península ibérica, en Los foros romanos de las provincias occidentales, Madrid, 173-178.

JIMÉNEZ, J. L., 1998, La multiplicación de plazas públicas en la ciudad hispanorromana, Empúries 51, 11-30.

JIMÉNEZ, J. L., 2004, Los escenarios de representación en las ciudades romanas de Hispania, en S. RAMALLO (coord.), La decoración arquitectónica en las ciudades romanas de Occidente, Universidad de Murcia, 379-403.

JIMÉNEZ, J. L., 2009, Los foros en las provincias de Hispania: estado de la cuestión, en J. M. NOGUERA (ed.), Fora Hispaniae. Paisaje urbano, arquitectura, programas decorativos y culto imperial en los foros de las ciudades hispanorromanas,

Monografías del Museo Arqueológico de Murcia 3, 37-64.

MANTAS, V. G., 2010, Ammaia e Civitas Igaeditanorum. Dois espaços forenses lusitanos, en T. NOGALES (ed.), Ciudad y foro en Lusitania Romana, Studia Lusitana 4, Mérida, 167-188.

MAR, R. y RUIZ DE ARBULO, J., 1990, El foro de Ampurias y las transformaciones augusteas de los foros de la Tarraconense, en W. TRILLMICH y P. ZANKER (eds.), Stadtbild und Ideologie. Die Monumentalisierung hispanischer Städte zwischen Republik und Kaiserzeit, Múnich, 145-164.

MAR, R., RUIZ DE ARBULO, J. y VIVÓ, D., 2010, El foro de la colonia Tarraco entre la República y el Imperio, Simulacra Romae II. Rome, les capitales de province (capita provinciarum) et la création d'un espace commun européen. Une approche archéologique,
Bulletin de la Société archéologique champenoise 19, Reims, 39-70.

MAR, R., RUIZ DE ARBULO, J., VIVÓ, D. y BELTRÁN-CABALLERO, J. A., 2015, Tarraco: Arquitectura y urbanismo de una capital provincial romana. Volumen I: De la Tarragona ibérica a la construcción del templo de Augusto, Documents d'Arqueologia Clàssica 5, Tarragona.

MARFIL, F., BERMEJO, J. y CAMPOS, J. M., 2018, La arquitectura forense en los Conventus Hispalensis y Astigitanus: testimonios materiales y síntesis, en J. M. CAMPOS y J. BERMEJO (eds.), Ciudades romanas de la Provincia Baetica. Corpus Vrbium Baeticarum: Conventus Hispalensis et Astigitanus. CVB I, Onoba Monografías 2, Universidad de Huelva, 273-306.

MÁRQUEZ, C., 1998, La decoración arquitectónica de Colonia Patricia. Una aproximación a la arquitectura y al urbanismo de la Córdoba romana, Córdoba.

MÁRQUEZ, C., 2014, El programa iconográfico del foro, en C. MÁRQUEZ, J. A. MORENA y A. VENTURA, Torreparedones - Baena, Córdoba-. Investigaciones arqueológicas (2006-2012), Universidad de Córdoba - Ayuntamiento de Baena, Córdoba, 86-97.

MARTIN, R., 1972, Agora et Forum, Mélanges de l'Ecole française de Rome. Antiquité, t. 84, n. ${ }^{\circ}$ 2, 903-933 [en línea]. Disponible en <https:// www.persee.fr/doc/mefr_0223-5102_1972_ num_84_2_937>.

MARTíN-BUENO, M., 1987, El foro de Bilbilis (Calatayud, Zaragoza), Los foros romanos de las provincias occidentales, Madrid, 99-111.

MARTíN-BUENO, M. y SÁENZ, J. C., 2004, Los programas arquitectónicos de época julio-claudia de Bilbilis, en S. F. RAMALLO (ed.), La decoración arquitectónica en las ciudades romanas de Occidente, Universidad de Murcia, 257-273.

MARTíNEZ, S., 2010, El foro romano de Termes (Hispania Citerior). Síntesis histórica, arqueológica y topográfica. S. I a. C. - s. II d. C., Archivo Español de Arqueología 83, 221-266. 
MATEOS, P. y PIZZO, A., 2014, La basílica de Contributa Iulia (Medina de las Torres, Badajoz), Zephyrus LXXIV, 181-201.

MENEGHINI, R., 2009, I Fori Imperiali e i Mercati di Traiano. Storia e descrizione dei monumenti alla luce degli studi e degli scavi recenti, Roma.

MENEGHINI, R. y SANTANGELI, R., 2007, I Fori Imperiali. Gli scavi del Comune di Roma (1991-2007), Viviani Editore, Roma.

MORÍN, J. y RIBERA, A., 2015, Los foros de Valentia y Ercavica. Dos modelos de crisis urbana a finales del Alto Imperio, en L. BRASSOUS y A. QUEVEDO (eds.), Urbanisme civique en temps de crise. Les espaces publics d'Hispanie et de l'Occident romain entre les $I I^{e}$ et $I V^{e}$ S., Madrid, 105-125.

NOGALES, T. (ed.), 2009, Ciudad y foro en Lusitania Romana, Studia Lusitana 4, Mérida.

NOGUERA, J. M. (ed.), 2009, Fora Hispaniae. Paisaje urbano, arquitectura, programas decorativos $y$ culto imperial en los foros de las ciudades hispanorromanas, Monografías del Museo Arqueológico de Murcia 3.

OLCINA, M., GUILABERT, A. y TENDERO, E., 2013, La curia de Lucentum, en B. SOLER, P. MATEOS, J. M. NOGUERA Y J. RUIZ DE ARBULO (eds.), Las sedes de los ordines decurionum en Hispania. Análisis arquitectónico y modelo tipológico, Anejos de Archivo Español de Arqueología LXVII, Mérida, 165-191.

PONTE, M. S., 2010, O Forum de Seilium/Sellium (Tomar), en T. NOGALES (ed.), Ciudad y foro en Lusitania Romana, Studia Lusitana 4, Mérida, 325-332.

RAMALLO, S. F. (ed.), 2004, La decoración arquitectónica en las ciudades romanas de Occidente, Universidad de Murcia, Murcia.

REMESAL, J., 2005, La política de César y sus repercusiones en la Bética, en J. F. RODRÍGUEZ, E. MELCHOR y J. MELLADO (coords.), Julio César y Corduba: tiempo y espacio en la campaña de Munda (49-45 a. C.), Córdoba, 469-476.

ROMERO, L., 2014, Los foros hispanorromanos del conventus Caesaraugustanus, Cuadernos de
Arqueología de la Universidad de Navarra 22, 149-217.

RUIZ BUENO, M. D., 2018, Dinámicas topográficas urbanas en Hispania. El espacio intramuros entre los siglos II y vII d. C., Bari.

RUIZ DE ARBULO, J., 2015, Tarraco y Augusto entre la República y el Imperio, en J. LÓPEZ VILAR (ed.), Actas Segundo Congreso Internacional de Arqueología y Mundo Antiguo, Tarragona, 151-166.

RUSSELL, J., 1968, The Origin and Development of Republican Forums, Phoenix 22/4, 304-336.

SCHATTNER, T., 2003, Munigua: cuarenta años de investigaciones, Junta de Andalucía, Instituto Arqueológico Alemán, Sevilla.

SILLIÈRES, P., 1997, Baelo Claudia: una ciudad romana de la Bética, Collection de la Casa de Velázquez 61, Madrid.

SIMÕES, M. H., 2010, Os fora de Bobadela (Oliveira do Hospital) e da Civitas Cobelcorum (Figueira de Castelo Rodrigo), en T. NOGALES (ed.), Ciudad y foro en Lusitania Romana, Studia Lusitana 4, Mérida, 47-67.

SOLER, B., MATEOS, P., NOGUERA, J. M. y RUIZ DE ARBULO, J. (eds.), 2013, Las sedes de los ordines decurionum en Hispania. Análisis arquitectónico y modelo tipológico, Anejos de Archivo Español de Arqueología LXVII, Mérida.

TORELLI, M., 2003, Chalcidicum. Forma e semantica di un tipo edilizio antico, Ostraka XII/2, 215-238.

TORELLI, M., 2005, Attorno al Chalcidicum: problemi di origine e diffusione, en X. LAFON y G. SAURON (coords.), Théorie et pratique de l'architecture romaine. Etudes offertes à Pierre Gros, Aix-en-Provence, 23-37.

TORRECILLA, A., 2007, Los macella en la Hispania romana. Estudio arquitectónico, funcional y simbólico [en línea], Universidad Autónoma de Madrid. Disponible en <http://hdl.handle. net/10486/3141>. [Tesis doctoral inédita].

VALLORI, B., 2012, Urbanisme $i$ arquitectura pública a la ciutat romana de Pollentia (Alcúdia, Mallorca). Segles II a. C. - III d. C., Universitat de 
Barcelona. Disponible en <http://hdl.handle. net/10803/89769>. [Tesis doctoral inédita].

VAQUERIZO, D., 2011, Corduba, ciudad puente, en M. D. BAENA, C. MÁRQUEZ y D. VAQUERIZO (eds.), Córdoba, reflejo de Roma. Catálogo de la exposición, Córdoba, 182-186.

VENTURA, A., 2006, El Forum Augustum: reflexiones sobre su configuración arquitectónica y su funcionalidad judicial (a propósito de la Basilica Antoniarum Duarum), Romula 5, 59-84.

VENTURA, A., 2007, Reflexiones sobre la arquitectura y advocación del templo de la calle Morería en el Forum Adiectum de Colonia Patricia Corduba, en T. NOGALES y J. GONZÁLEZ (eds.), Culto imperial: política y poder, L'Erma di Bretschneider, Roma, 215-238.

VENTURA, A., 2009, Las élites de Colonia Patricia, año 5 a. C.: un ejemplo de puesta en escena literaria y monumental, Anejos de Archivo Español de Arqueología XLVIII, Mérida, 375-395.
VENTURA, A., 2014, El foro, en C. MÁRQUEZ, J. A. MORENA y A. VENTURA, Torreparedones Baena, Córdoba-. Investigaciones arqueológicas (20062012), Universidad de Córdoba - Ayuntamiento de Baena, Córdoba, 69-86.

VENTURA, A., ANDREU, J. y ROMERO, L., 2018. Equites del ala Tauriana al servicio de Roma: los Sempronii del oppidum de Los Bañales (Hispania Citerior), Gladius XXXVIII, 35-45.

VIDAL, J. M. y GONZÁLEZ, M. L., 2018, Asturica Augusta: actualización de su urbanismo a la luz de las excavaciones recientes, en S. MARTÍNEZ, J. SANTOS y L. J. MUNICIO (eds.), El urbanismo de las ciudades romanas del valle del Duero, Anejos de Segovia Histórica 2, 273-297.

ZANKER, P., 1984, Il foro di Augusto, Fratelli Palombi, Roma.

ZEVI, F., 1993, Chalcidicum, LTUR I, Roma. 
